Article

\title{
Evidence-Based Educational Innovation Model Linked to Digital Information Competence in the Framework of Education 4.0
}

\author{
Celia Paola Sarango-Lapo ${ }^{1, * \mathbb{D}}$, Juanjo Mena ${ }^{2}$ and María Soledad Ramírez-Montoya ${ }^{3}$ \\ 1 Technologies for Education, Universidad Técnica Particular de Loja, Loja 110107, Ecuador \\ 2 Department of Education, Universidad de Salamanca, 37007 Salamanca, Spain; juanjo_mena@usal.es \\ 3 Institute for the Future of Education, Tecnologico de Monterrey, Monterrey 64849, Mexico; solramirez@tec.mx \\ * Correspondence: cpsarango@utpl.edu.ec; Tel.: +593-959-531-587
}

check for

updates

Citation: Sarango-Lapo, C.P.; Mena,

J.; Ramírez-Montoya, M.S.

Evidence-Based Educational

Innovation Model Linked to Digital

Information Competence in the

Framework of Education 4.0.

Sustainability 2021, 13, 10034. https://

doi.org/10.3390/su131810034

Academic Editor: Cecilia Ruiz

Esteban

Received: 22 July 2021

Accepted: 31 August 2021

Published: 8 September 2021

Publisher's Note: MDPI stays neutral with regard to jurisdictional claims in published maps and institutional affiliations.

Copyright: (C) 2021 by the authors Licensee MDPI, Basel, Switzerland. This article is an open access article distributed under the terms and conditions of the Creative Commons Attribution (CC BY) license (https:// creativecommons.org/licenses/by/ $4.0 /)$.

\begin{abstract}
Education 4.0 promotes visualizing how teachers' traditional digital competencies adopt innovative practices. The present research analyzes the relationship between the perceived digital information competencies (DICs) of university teachers and the implementation of evidence-based, innovative actions (EBEI) in a model that supports innovative practices. The research method applied was the mixed method. In the quantitative phase, the final sample consisted of 271 teachers. The ad hoc digital competency-open educational resource scale (DC-OER) was applied to measure their perception of DIC. In the qualitative phase, 15 teachers were interviewed. The results showed (a) a close relationship between the fulfillment of EBEI and the support of DIC; (b) in quantitative results, in most cases, the means are close to the central value 3, and the standard deviation is close to 1 , which indicates higher DIC; (c) the qualitative results indicate that teachers search, select, evaluate information, and produce new knowledge; and (d) the theoretical model of EBEI links DIC to the formation of digital citizenship. The data can be of value to the academic community in relevant environments within the framework of Education 4.0. As a future line of research, we envision analyzing the perceived digital competencies of teachers versus their effective behavior.
\end{abstract}

Keywords: educational innovation; higher education; education 4.0; digital competencies; innovation-based evidence

\section{Introduction}

Due to the accelerated developments in technology, especially in education, it has become necessary for teachers to adapt to change. Because of this, it has been crucial for them to transform their knowledge and skills to move from traditional teaching to innovative practices supported by technological resources [1,2]. Specifically, Education 4.0, with advanced connectivity supporting more outstanding virtualization processes [3], recognizes the role of teachers in educational processes and their contribution to the improvement of education. Education 4.0 is understood as that which promotes the application of physical and digital resources that provide innovative solutions to the current and future challenges of society [4]. Therefore, it promotes changing the vision of teachers' digital competencies from old skills to innovative practices. In the context of education 4.0 [5], a teacher's profile describes a specialized professional with digital competencies oriented to innovation, problem-solving, entrepreneurship, collaboration, connection, and understanding the needs of society. Acquiring these competencies requires stimulation through practical experiences [6].

Education 4.0, unlike traditional education, seeks to provide solutions to these challenges. Therefore, the integration of innovative pedagogies supported by emerging technologies [7] and best practices [4] provides these solutions. However, they require the acquisition and development of digital competencies and those that lead to reflection, 
problem-solving, informed decision-making, and practical experience, to develop innovative solutions. Therefore, evidence-based educational innovation (EBEI) is presented as an alternative that relies on practical experiences where digital competencies (DCs) in general and digital information competencies (DICs) in particular can be stimulated.

In this area, several applications of EBEI have been carried out. Studies such as [8] mention that EBEI responds to the need to offer relevant and updated teacher training to contribute with experiences in technological innovation. However, [9] adds that this can happen as long as teachers are committed and motivated to change. Likewise, [10] states that EBEI promotes training in digital competencies to manage technological resources that connect knowledge with teaching practice and produce innovation [11]. Thus, EBEI promotes learning conceived from practical experiences with technology; this aligns with [12] that these changes reconfigure the teacher-student relationship.

The EBEI linked to DIC tries to bring the teacher closer to a reflective performance model. [13] points out that a teacher who has developed DC is inquiring, creative, and reflective. Thus, it is expected that, in a virtual environment where information is constantly updated, a citizen (teacher, student, citizen, and general) can discern the appropriate information [14] and evaluate it [15]. Therefore, DIC promotes the ability to deal with information and leveraging it to build knowledge, learn, and respond to problems or needs in everyday practice [16]. DIC involves recognizing the need for information, locating it in open [17] or closed sites, analyzing it, managing it, storing it, and transforming it into knowledge [18-20]. Thus, DIC also promotes communication and the dissemination of information [21,22]. Its purpose is to achieve collaboration and exchange to facilitate the construction of knowledge [23]. Some are the theoretical CD frameworks that have been proposed and in which CDIs are highlighted among them is the DigComEdu [24], the Association of College and Research Libraries [18], DigComEdu Chek-In [25], the common framework of digital teaching competence of the National Institute of Educational Technologies and Teacher Training [26], DigCom [27], among others.

Based on these ideas, this article aims to describe teachers' perception of the DIC and their relationship to innovative actions that contribute to their teaching practice, an innovative model also part of the EBEI methodology. The research was a quantitative study to verify the teacher's perception of the DIC. It was complemented by a qualitative study on the DIC, which was applied to develop an end-of-course task that included the EBEI steps. Then it proposed a model of educational innovation based on evidence linked to digital competencies, intending to provide information for training processes that are of value to teachers, researchers, administrators, and trainers seeking educational innovation. The article is presented in three sections: The study method (with design, population and sample, instruments, data collection, and analysis), results and discussion, and conclusions.

\section{Materials and Methods}

\subsection{Design}

The explanatory-sequential, mixed research method outlined by [28] was used to develop the research. The design was chosen because qualitative data help explain and deepen the initial quantitative statistical results to answer the research question: What is the relationship between the perceived capability of digital information competence and the fulfillment of innovation actions based on EBEI? Therefore, the notation followed was QUAN->qual. Greater emphasis was given to the data (CUAN), since it was important to first quantitatively measure the perception of the university teacher's CDI through a DC-OER scale consisting of 16 items, with five Likert-type response options: no mastery, little mastery, regular mastery, good mastery and excellent mastery; and then based on these results proceed to deepen and complement them through the interview or data (qual). They indicated that the qualitative method complements quantitative data analysis [29], allowing inferences to be made with greater precision. 


\subsection{Sample}

The study's population was located in a higher education institution in southern Ecuador and comprised bimodal university teachers (i.e., face-to-face and distance teachers). In particular, the quantitative study sample corresponded to 277 teachers participating in an evidence-based educational innovation course with open educational resources (OER). The qualitative study sample was composed of 15 teachers participating in the quantitative phase and the classroom innovation course; they were interviewed about the DIC applied in developing the end-of-course assignments. EBEI suggested their relationship with the steps. Their participation in the courses made them an ideal sample for this study. The level of education of the teachers ranged from bachelor's to masters and doctoral degrees. The areas of knowledge to which they belonged were Socio-Humanistic, Technical, Biological, Biomedical, and Administrative.

\subsection{Instruments}

The instruments used were a questionnaire and an interview, which experts previously validated for clarity of wording, dimensional coherence, and sufficiency of items. The questionnaire's objective was to determine the teacher's perception of the DIC, and it included sociodemographic and research questions. The research questions used the ad hoc DC-OER scale consisted of 16 items, with five Likert-type response options: No mastery, little mastery, fair mastery, good mastery, and excellent mastery, which were based on the Information and information literacy area of the model (INTEF, 2017). Validated through confirmatory factor analysis [30], they were oriented to measure digital information competencies (DIC). There was also a research question to determine the fulfillment of innovative actions based on EBEI [31]; its results were considered to complement the proposed innovation model. The objective of the interview was to inquire about the DIC (search, selection, evaluation, and use and dissemination of evidence/information) applied in the development of the task (the innovation proposal) based on EBEI, which integrated six steps: (1) Delimit the innovation object; (2) search for evidence available in the bibliography or specialized sites; (3) formulate the innovation; (4) apply the innovation; (5) evaluate the innovation, and (6) publish and disseminate the innovation results. Therefore, the categories analyzed were (1) digital information competencies (DIC) and (2) evidencebased educational innovation (EBEI).

\subsection{Procedure}

The instruments were applied in two phases. In phase 1, quantitative data with the support of the DC-OER scale were collected using the Survey Monkey tool and processed using SPSS software. The online instrument was accessible only to the sample of participants, and the anonymity and confidentiality of the responses were guaranteed. Once the quantitative data were collected, a review of the subjects' responses was carried out in search of incomplete or incorrectly completed questionnaires. It was found that the answers of six of the subjects in the sample were not correct; therefore, the final sample contained 271 participants. Once these quantitative results were obtained, we proceeded to delve using qualitative data collection techniques. In this phase, we analyzed the responses in the 15 interviews with teachers about their experience in handling the information necessary to develop their integrative task and link it with the EBEI steps of the educational innovation course in the classroom. The answers were categorized based on the literature. The qualitative data were processed using the Maxqda2020 release 20.4.1 software.

\subsection{Data Analysis}

As the mixed method of explanatory-sequential type was applied in this research, quantitative information was obtained first for the data analysis and then deepened through qualitative data collection techniques [32]. For the analysis of the quantitative data, SPSS software was used to calculate descriptive statistics (means and standard deviations) on the perception of DIC. For the qualitative data analysis, the data from the interviews were 
processed with Maxqda2020 software, using categories and subcategories based on the literature. It is worth emphasizing again that the qualitative results complemented the quantitative results.

\section{Results}

This section presents the results according to the proposed objectives: (1) Perception of DIC and its linkage with the EBEI steps and (2) evidence-based educational innovation model linked to DIC.

\subsection{Bimodal Teachers' Perceptions of the DIC and Their Link to EBEI}

The DC-OER scale consisted of 16 items, with five Likert-type response options: No mastery, little mastery, fair mastery, good mastery, and excellent mastery. Thus, the scale measured the subjects' perceived DIC in each aspect considered, that is, their specific self-efficacy in this domain [33,34]. Of the 16 items of the scale, four corresponded to competencies in information search, selection, and evaluation (Ia, Ib, Ic and Id); three items corresponded to competencies in information storage and retrieval (IIa, IIb, IIc); three items corresponded to competencies in information communication and dissemination (IIIa, IIIlb, IIIc); finally, six items corresponded to competencies in the use of OER (IVa, IVb, IVc, IVd, IVe, IVf). Table 1 shows the means and standard deviations obtained in the scale items by the sample of subjects. Those items below three would show lower proficiency in the skill assessed, while scores above three would indicate higher proficiency.

Once the quantitative results were obtained, it became necessary to complement them qualitatively to understand how natural the DIC occurrences were. The experience in applying them during the development of the innovation proposal with EBEI (the integrating task) corresponds to category 2. To this end, 15 professors (seven with master's degrees and eight with doctoral degrees) participating in the quantitative phase in the four areas of knowledge were interviewed. Their interview responses were coded, categorized, and subcategorized based on the literature as described below.

Category: Search, selection, and evaluation of information. This aspect was relevant for the teaching and research performance and necessary for the task's development. We inquired about the teachers' sources-of-information preferences, the main problems accessing the information to present, the information search techniques applied, and the procedure followed in selecting and evaluating the information incorporated into the task.

Regarding the professors' responses to information sources (which they used to perform the integrative task), as shown in Figure 1, the Scopus database was their primary source of consultation (to a lesser extent, the WOS and Science Direct databases), followed by the Google Scholar search engine. Official data websites for data statistics, bulletins, and notifications were other sources consulted, depending on the nature of the subjects or search purposes. Additionally, open-access information sources, such as educational resources available in repositories or open sites, were consulted by some teachers. Google databases, ResearchGate, Mendeley, and social networks also served this purpose for teachers. Therefore, the teachers indicated that this competency allowed them to delimit the object of innovation (step I of EBEI) and search for evidence (step II of EBEI). Through the consultation sources, they identified the educational practice they proposed to improve and provided evidence of good practices. 
Table 1. Means and standard deviations of the 16 items of the DC-OER Scale corresponding to the sample of subjects.

\begin{tabular}{|c|c|c|}
\hline Title 1 & Means & S.D. \\
\hline $\begin{array}{l}\text { Ia. Competence to search, select, and evaluate information (knows how to surf the internet and search } \\
\text { for information). }\end{array}$ & 3.91 & 0.805 \\
\hline $\begin{array}{l}\text { Ib. Competence in searching, selecting, and evaluating information (uses keywords related to the } \\
\text { information needed and uses operators ("and" or " or") to search for information). }\end{array}$ & 3.66 & 0.958 \\
\hline $\begin{array}{l}\text { Ic. Competence to search, select, and evaluate information (selects the information according to the search } \\
\text { purposes and verifies its license to use) }\end{array}$ & 3.44 & 0.925 \\
\hline $\begin{array}{l}\text { Id. Competence to search, select, and evaluate information (critically evaluates the results of information } \\
\text { integrated into his/her knowledge and they are consistent with the desired purposes). }\end{array}$ & 3.78 & 0.889 \\
\hline $\begin{array}{l}\text { IIa. Competence for storing and retrieving information produced (stores information in open access } \\
\text { repositories, open sites such as blogs, wikis, or private sites such as databases or digital libraries). }\end{array}$ & 2.88 & 1.168 \\
\hline $\begin{array}{l}\text { IIb. Competence for the storage and retrieval of information produced (adds metadata and creative } \\
\text { commons licenses to the information stored, to aid in the visibility of the information) }\end{array}$ & 2.43 & 1.175 \\
\hline $\begin{array}{l}\text { IIc. Competence in storing and retrieving information produced (understands the risks and advantages of } \\
\text { storing information publicly or privately). }\end{array}$ & 3.11 & 1.188 \\
\hline $\begin{array}{l}\text { IIIa. Competence for communicating information by technological means. Selects the means of } \\
\text { communication that best suit his/her purposes (e.g., Skype, Hangout, email, etc.) }\end{array}$ & 3.71 & 0.958 \\
\hline $\begin{array}{l}\text { IIIb. Competence for communicating information by technological means (knows how to convey ideas in } \\
\text { written and verbal form using synchronous and asynchronous technologies). }\end{array}$ & 3.75 & 0.822 \\
\hline $\begin{array}{l}\text { IIIc. Competence for the communication of information by technological means (disseminates the results of } \\
\text { the information produced in open access repositories, open sites such as blogs, wikis, or open media (online } \\
\text { seminars), or private sites such as databases or digital libraries). }\end{array}$ & 2.79 & 1.088 \\
\hline $\begin{array}{l}\text { IVa. Appropriation of digital competence in the use of Open Educational Resources (uses OER videos, } \\
\text { images, audios with Creative Commons license in teaching planning). }\end{array}$ & 3.48 & 0.976 \\
\hline $\begin{array}{l}\text { IVb. Appropriation of digital competence in the use of Open Educational Resources Consults and cites OER } \\
\text { (Creative Commons licensed articles) as support for their research. }\end{array}$ & 3.32 & 1.044 \\
\hline $\begin{array}{l}\text { IVc. Appropriation of digital competence in the use of Open Educational Resources (in the classroom, } \\
\text { designs activities with OER to reinforce learning). }\end{array}$ & 3.31 & 0.958 \\
\hline $\begin{array}{l}\text { IVd. Appropriation of digital competence in the use of Open Educational Resources (promotes interest in } \\
\text { using OER among students, colleagues, and environment). }\end{array}$ & 3.19 & 1.032 \\
\hline $\begin{array}{l}\text { IVe. Appropriation of digital competence in Open Educational Resources (promotes interest in publishing in } \\
\text { open source among students, colleagues, and environment. }\end{array}$ & 2.81 & 1.063 \\
\hline $\begin{array}{l}\text { IVf. Appropriation of digital competence in the use of Open Educational Resources (collaborates in } \\
\text { academic networks for discussion and research on OER). }\end{array}$ & 2.28 & 1.129 \\
\hline
\end{tabular}

\section{toogle Scholar Open access information} ScienceDirect Scoplus

ResearchGate Mendeley Wos Poogle Social networks Official site reports

Figure 1. Cloud of preferred sources of information. 
Regarding the problems in accessing information, all the interviewees agreed that access to relevant information in paid databases was the main one. According to one interviewee, "This is a concern because there is much good information that cannot be accessed" (E062). Likewise, some teachers indicated that access to the databases available through the virtual library was limited from their homes because "it can only be accessed from the university premises" (E065). To a lesser extent, some indicated language as another research problem since "most of the good information is in English, which makes interpretation difficult" (E066). Likewise, lack of time turned out to be an essential factor. According to most of them, "time is necessary to make a good search and selection of information" (E069), and "There is so much to read, and it takes time" (E066). Finally, two interviewees (E063, E069) pointed out that the lack of knowing information search strategies prevented them from doing an advanced search for information. It can be inferred that these problems had some impact on the task's development, especially in the consultation and citation of paid information because they could only access the summary or abstract.

Regarding the search techniques applied by the interviewees, Figure 2 shows that the most frequently used technique was the keyword search according to their research purposes. This form of research is closely linked, as indicated by the highlighted (thick) lines, to the use of operators and years of publication (no more than five years old). Another technique was the search by author(s) and the search by journal name. The teachers indicated that applying these search techniques allowed them to specify and refine the results to develop steps I (delimiting the object of innovation) and II (search for evidence).

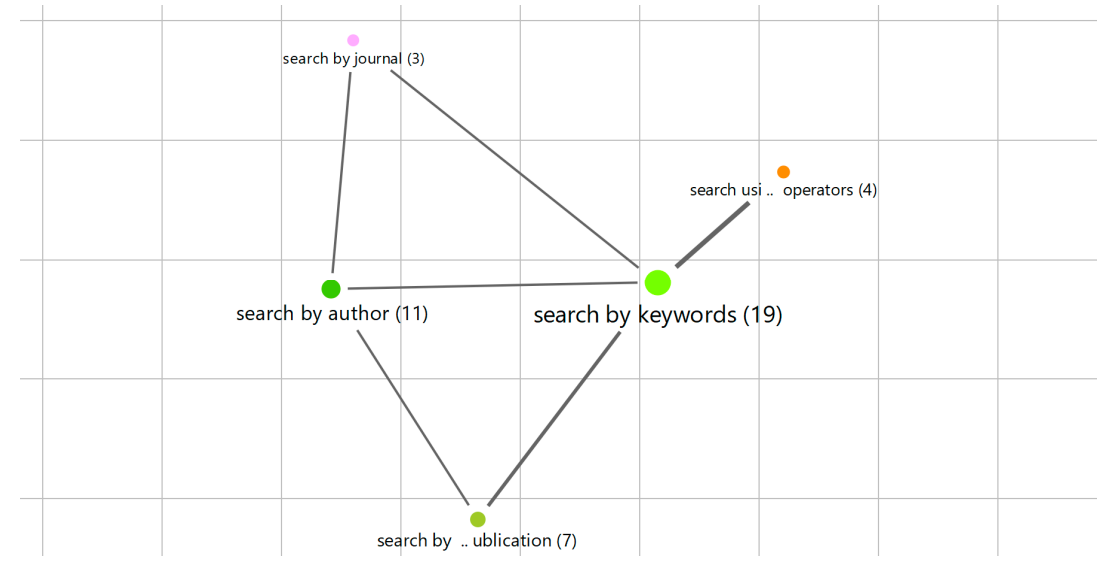

Figure 2. Map of clusters of applied information search techniques.

Regarding selecting and evaluating the information, the professors selected and evaluated the information per the search purposes and the innovation they proposed. Only then did they establish the timeliness of the information (no more than five years old). Likewise, another important criterion was that the authors of the selected information were referents in the subject (i.e., they mainly were cited) and that the information found would be helpful for the student. They indicated that these competencies favored the fulfillment of steps I (delimiting the object of innovation), II (search for evidence) to support the proposal with other good practices, IV (application of the innovation) in identifying the phases of the innovation, and the instruments to evaluate the innovation (step V). Additionally, the professors reported that they selected the information based on the ranking of the journals and the preference for open information or a creative commons license.

Category: Information storage. In this aspect, the responses were diverse. Most interviewees indicated that their primary technological tool for information storage to develop their task was their personal computer, and OneDrive was their preferred storage manager. The latter was especially preferred because it allowed teachers to store in the cloud the information required to delimit the innovation (step I of EBEI) and the information result- 
ing from fulfilling step II of EBEI; thus, having it available from anywhere with internet access. It is noteworthy that they considered the bibliographic manager Mendeley as a tool for storing, organizing, and consulting the information that served them to develop their task. "Mendeley is a tool that, besides allowing citation and bibliography management, serves well to store information and consult and analyze it" (E063); "Mendeley allowed me to organize the information in folders by research variables," said one of the respondents (E065). Additionally, some pointed to social and open networks such as YouTube that allowed them to store recorded videos, which were part of their innovations. In addition, they had the institutional virtual learning platform and the repository of open educational resources, which was generally used to store resources produced for students and others who were participating in the innovation project proposals.

Category: Use and processing of information. In this category, teachers indicated that they used it to formulate, implement, and evaluate the innovation (steps III, IV, and V of EBEI). For this, they applied the following criteria: they proceeded to contrast it: "I contrasted the selected information with what I intended to do" (E063); "I contrasted the information among authors and incorporated my interpretation" (E065). They then synthesized the main ideas through diagrams, mind maps, graphic organizers, and matrices. Another said: "I always do mental maps of what I am reviewing, then I decide my central theme, and I gather everything linked to it" (E063). Another noted: "It helps me a lot to work with a matrix where I can record the most relevant data" (E066). Thus, many teachers indicated that they proceeded to create knowledge, respecting authorship. "I quote the authors that help me support my project" (E070); "I start writing my ideas, comparing them with what other authors say, quoting them, of course." (E072). It is striking that organizing the selected information was not considered a starting point within this category; perhaps they regarded it as implicit in the process.

Category: Communication and dissemination of information. The findings presented in Figure 3 indicated that the preferred means of the interviewees to communicate and disseminate the innovation results (EBEI step VI) were journals (open or closed). "I always choose to look for the highest Q1 journals, and, if not accepted, I try to improve the article for another journal" (E060), said one interviewee. "The truth is that I have never considered publishing only in open access. When I see events of interest to me and my work has a relevant impact both in journals and in congresses, only then do I send" (E067).

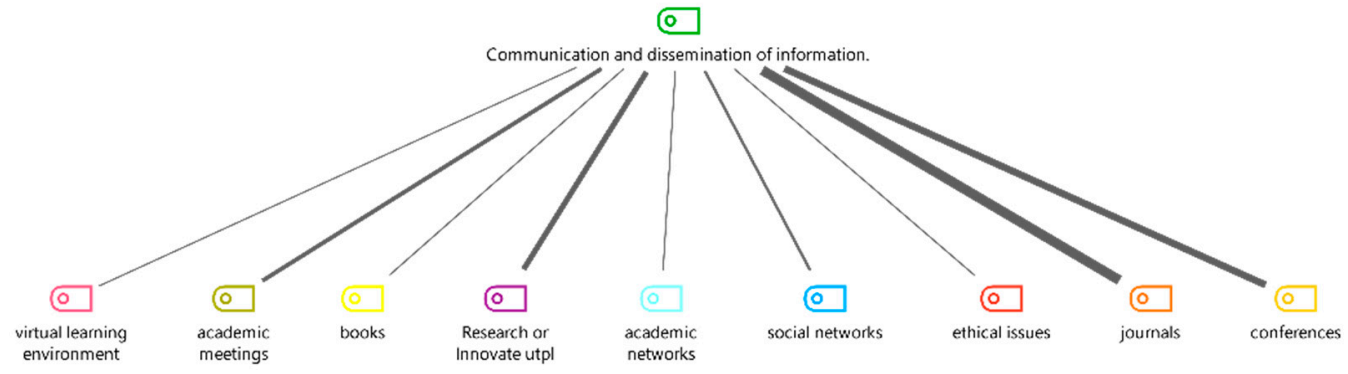

Figure 3. Category map: Communication and dissemination of information.

The second primary means of dissemination were congresses or conferences. "The interesting thing about these works is that I prepare the results to present them as papers in congresses" (E061); "The results of innovations I like to disseminate more often in congresses with ISBN proceedings" (E062). It is also interesting to know that the events of the institution under study (Research or Innovate UTPL) are attractive and acceptable by the teachers to publish their research: "The university provides spaces to disseminate the results of innovation practices" (E070); "I take advantage of Investiga UTPL to present research results" (E063); "In local university events, we present post-type results" (E068); "In the spaces of good teaching practices we were asked to present the information and results we have obtained from this good practice" (E068). 
To a lesser degree, academic networks such as ResearchGate, Google Scholar, and Academia Edu served as open technological means to communicate or disseminate information about innovation or research. They can also be used as a tool for research management: "Through these academic networks, I can check my citations" (E062). Likewise, social networks, Web 2.0 tools, and books were interesting means of communicating and disseminating information. Figure 3 presents the findings described above. In this figure, the line's thickness indicates the teacher's level of interest in publishing through that source. These findings allow visualizing the teachers' interest in disseminating and publishing the innovations (step VI of EBEI) in journals and conferences.

The qualitative results described above complemented the quantitative results since the aim was to deepen the teacher's experience in applying the DIC while developing the task that included the steps of the EBEI methodology. These results highlight some warning points that should be considered. These warning points mainly relate to the problems of information access. Paid databases, language, lack of time, and lack of knowledge of information search strategies hindered compliance with steps I and II of EBEI requested in the task. Second, concerning the competencies of selection and evaluation of information, few teachers mentioned verifying the licenses to use information, also necessary to enrich steps III, IV, and V of EBEI. Third, concerning information storage competencies, most interviewees coincided in using computers as technological storage resources, thus showing a lack of knowledge of other information storage sources, especially those with open characteristics. Finally, regarding the competency of communication and dissemination of information directly related to step VI of EBEI, attention should be paid to those aspects that allow teachers to share information to generate synergies and collaborate with the help of technology.

\subsection{Evidence-Based Model of Educational Innovation Linked to the DIC}

Based on the results in the previous section, we observed that DIC are necessary for the fulfillment of the EBEI steps, so a close relationship between the two can be inferred. Therefore, the educational innovation model linked to DIC considers the philosophical, theoretical, practical, political, and operational components proposed in teaching practice [35]. Figure 4 presents the proposed innovation model.

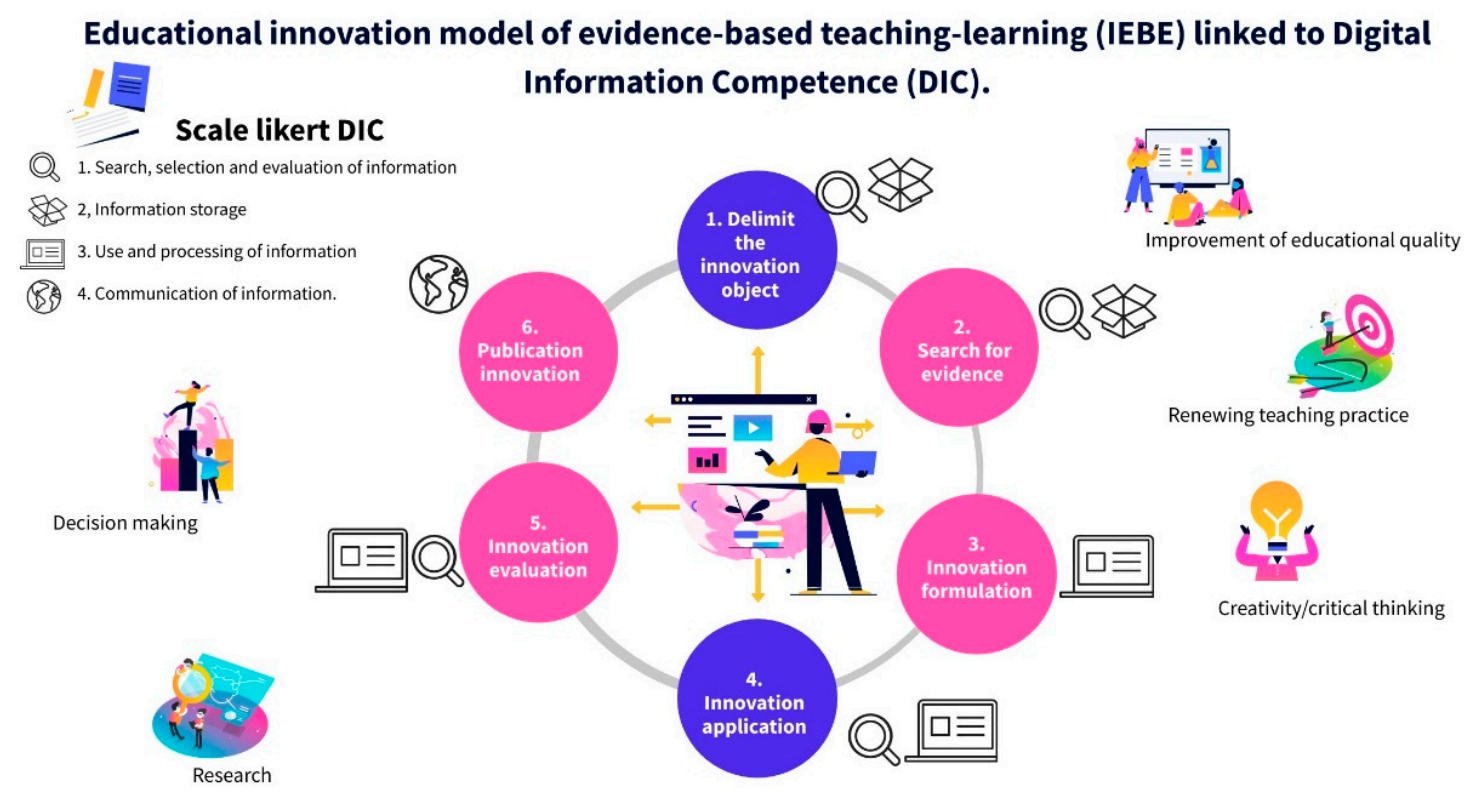

Figure 4. EBEI model linked to the DIC.

As shown in Figure 4, the proposed model is guided by UNESCO's sustainable development goal 4 (SDG4), which seeks to improve the quality of education to improve people's 
lives through sustainable development (political component or practical orientation) [36]. The ultimate goal of the model (the philosophical component) is for participating teachers to renew or update their practices by analyzing and disseminating innovative evidence supported by the DIC. This model is proposed as a theoretical teaching-learning model for applying knowledge (the theoretical component). Therefore, it seeks innovation in teaching practices, and its application depends on teachers' creativity. Hence, the innovation model intends that educational institutions find opportunities for internal innovation (the operational component), so from understanding reality, teachers individually or collaboratively propose innovative solutions with social impact through applying knowledge, decision making, and research [35].

The proposed model presents a six-step cycle of EBEI linked to DIC. It focuses on the participant, whose primary purpose is to improve their learning by formulating and implementing innovations based on evidence to solve a problem or respond to a need. The six steps of EBEI are (1) delimiting the object of innovation, (2) searching for evidence, (3) formulating the innovation. The teachers execute the steps: (4) Applying the innovation, (5) evaluating the innovation, and (6) diffusing and communicating the innovation sequentially [31], creatively implementing the innovation with the support of the DIC. Based on the evidence of good practice, the design and implementation of innovative proposals respond to a need or problem. The innovation results are disseminated and published as new evidence, contributing to the teacher's professional performance, as indicated by this research's results, which support the model's usefulness.

Executing step I, delimiting the object of innovation, is vital because it defines, as [37] points out, the need for change, the clarity offered by the transformation, the field it covers, and its practicality. This step must always be understood and appreciated with care [2]. It requires the competency of search, selection, evaluation, and storage of information that help delimit the subject from a critical analysis of evidence relevant to the innovation proposed. The delimitation requires that the selected innovation is relevant, practical, and pertinent. It must lead to asking valuable questions that contribute new knowledge about educational innovation.

On the other hand, in step II, the search for evidence or proven good practices goes hand in hand with the DIC (i.e., the correlation is very close) and this step becomes an essential and highly beneficial condition in the model. In this step, information search, selection, and evaluation skills are particularly required. This competency makes it possible to search for information in reliable, valid, and refereed sites such as paid databases or open databases in English and Spanish (see Figure 1). It is also possible to search for information by applying sensitive search techniques that facilitate the inclusion of relevant information, exclude irrelevant information, as shown in Figure 2, and critically evaluate and analyze the selected evidence. The information found should be critically evaluated and analyzed to determine its correlation with the search purposes, the timeliness of the information, the relevance of the author of the publication, and the information's usefulness for students.

In short, step III requires reflection and decision-making to formulate the innovation and know what has succeeded in other contexts. Hence, step II must be carried out with care and much attention [38]. The close relationship with information storage or management competency is also highlighted here, given that the information or evidence of good practices must be downloaded, stored, and organized for consultation. Its purpose is to support grounded knowledge for relevant decisions. The results pointed to Mendeley's bibliographic reference manager as a technological tool that allows this activity in the present investigation. Thus, in this step II, the need to apply research strategies can be glimpsed since they relate to the purposes pursued. Therefore, in line with [39], research is inherent to the educational process and essential to better learning.

To fulfill step III, formulating the innovation, teachers must pay much attention since its development should reflect the improvement of some aspects of educational practice. As described by [40], the formulation of innovation represents an opportunity for teachers to reflect on their practice, have greater empathy in their working relationships, and develop 
the exercise of research. Consequently, step III considers those ideas for processes, strategies, or activities that result from evaluating evidence applied in other successful contexts. In this step, the digital competency of using and processing information is fundamental; that is to say, it is required to contrast the evaluated information, synthesize the main ideas, and create new knowledge respecting the authorship, as shown in the results.

Step IV, applying the innovation, is conditioned by fulfilling the previous step. Formulating the innovation is necessary to apply it. Thus, the digital competence of searching, selecting, evaluating, and using information is required. In this step, the implementation of the innovation usually differs from what was initially planned, sometimes positively and sometimes negatively. When the innovation receives the expected acceptance and more participants are involved, no resistance to change is observed.

On the other hand, when there is no participation of the people involved, there is resistance to change. Hence, to fulfill this step, the person in charge must be prepared for the unexpected. Creativity becomes crucial to face the unexpected events that may arise when applying the innovation and making changes. In any case, preparation always has an advantage, especially when the project is integrated with specific conceptual and methodological coherence. The innovation's objective is detailed in interventional phases, the sample of participants is defined, and the data analysis techniques and the instruments to be used are proposed. It is in these aspects that the DIC are relevant. They allow using the critically evaluated information to design the interventional phases and instruments and determine the sample and the data analysis techniques based on the evidence. Therefore, in this step, it is essential to know in detail the conditions required for its implementation, establish contacts with the people involved, and prepare the necessary materials. In line with [39], we recommend documenting the processes of applying or implementing the innovation, recording what happens, the changes that occur, how they are addressed, and the decisions. This information will be vital for the next step, which is the evaluation.

The evaluation of innovation, to fulfill step $\mathrm{V}$, must be applied to the innovation to evaluate it. In this step, it is necessary to define and apply the instruments to evaluate the innovation. The qualitative, quantitative, or mixed data analysis techniques assess if the innovation implemented had the expected impact. Therefore, whether the achievement of the objectives is verified or not, the question in step I is answered. This step allows determining if the changes achieved the expected levels. Therefore, the methods' results according to the objectives follow in the subsequent discussion. The conclusions derived from the innovation try to give meaning and provide knowledge about it. For the development of these aspects, the competencies of search, selection, evaluation, and use of information are necessary because they allow corroborating or counteracting the results obtained with the proven evidence in other studies.

Finally, to complete step VI, publication and dissemination of the innovation, steps I to $\mathrm{V}$ must be completed. The link with the information communication competencies is highlighted since these allow the teacher to select the most appropriate technological platforms for the publication and dissemination of the innovation's results. Once the six steps of the model have been fulfilled, the transfer of acquired knowledge can be achieved, and the new evidence can guide teaching practice. The results indicated that the preferred means for publishing and disseminating innovation results are peer-reviewed journals (open or closed), congresses, institutional conferences, and social sites such as ResearchGate (see Figure 3).

\subsection{Analysis and Interpretation of Results}

The following is the analysis and interpretation of the main results responding to the research objective to analyze the relationship between the perceived capacity of university teachers' DIC and the implementation of innovative actions based on EBEI evidence. For the analysis and interpretation, the quantitative results on the perception of DIC were the starting point. Therefore, their contribution was based on making known the level of DIC perception held by the teacher. Those items below 3 would show lower competence 
in the assessed skill, while scores above 3 would indicate higher competence. Then, qualitatively, through interviews with teachers, we proceeded to deepen and complement the quantitative results. The interview was oriented to learn about the application of the DIC in the development of the task that integrated the steps of the EBEI.A teacher with advanced digital competencies ensures optimal use of information. The quantitative findings found in the search, selection, and evaluation of information show that bimodal university teachers presented higher digital competencies, with a mean higher than 3 in the items Ia, Ib, Ic, Id of Table 1. These findings are corroborated in light of the qualitative results. According to the literature, the digital competence of searching, selecting, and evaluating information allows the teacher to leverage the contents available on the internet and critically evaluate them for their teaching and research functions [1,18]. Consequently, bimodal teachers with competency in searching, selecting, and evaluating information available on the internet take advantage of the content potential for their teaching and research functions. They must select their information with quality criteria (reliability, veracity, and suitability) and analyze it critically.

Additionally, a teacher with the skills to navigate and search for information on the internet is positioned to find relevant information for the teaching task. Thus, in the quantitative results in item (Ia) of Table 1, we can see that bimodal university teachers perceive themselves as having a good command of the skills to surf the internet and search for information. These results coincide with the qualitative results of Figure 1, which indicates that the primary sources of information chosen on the Internet are Scopus and Google Scholar, followed by other sources. This aspect contributed to steps I and II of EBEI because it was necessary to identify the educational practice that the teacher wants to improve supported by evidence and qualitatively supported in the findings. These findings are similar to those found in the study by [16]. Teachers present a high self-perception in the ability to search for information and locate it quickly and efficiently. Therefore, it can be deduced that bimodal teachers have a good command of how to search for information, locate it, and integrate it into teaching and research activities, competencies necessary for steps I (delimitation) and II (search for evidence) of EBEI.

The use of information search techniques allows the teacher to find information with greater precision. In item $(\mathrm{Ib})$ of Table 1, the quantitative results indicate that the bimodal teacher uses logical operators and keywords as basic information search techniques. These findings are corroborated with those represented in Figure 2. A close relationship is expressed between the keyword search and operators' support, contributing to the fulfillment of steps I and II of EBEI. [14] states that a citizen must rethink his search practice, learning information search techniques, from basic to complex, to refine the results. Therefore, bimodal teachers consistently command basic search techniques to locate information in various sources, required for steps I (delimitation) and II (search for evidence) of EBEI. However, training in advanced search techniques that help refine the targeted information is recommended.

A characteristic of the DC is that it allows the teacher to select the information and treat it as creatively as possible. In item (Ic) of Table 1, the teachers state that they select the information by establishing criteria that allow them to choose what is consistent with the search purposes, and they verify its license for use. This aspect is closely related to step II of EBEI. These results are corroborated with the findings described qualitatively. However, we observed that, in this process, verifying the license of use is mentioned infrequently. In this aspect, in the opinion of [2], the trend in educational innovation is toward open education (i.e., where the potential offered by OER for teaching or research can be exploited). In this sense, it can be inferred that, although teachers perceive themselves as having regular competencies in information selection, it is necessary to reinforce training and awareness. Awareness of information containing creative commons licenses must be brought to bear since they constitute innovative teaching-learning and research.

A teacher with digital competencies can determine the value of information. In item (Id) of Table 1, teachers indicated that they perceive themselves as critical evaluators of 
the information found. This is corroborated with the qualitative findings for evaluating the credibility of the information found and analyzing it critically for decision making and knowledge construction. This information is considered when formulating the innovation, especially in analyzing the needs of the educational context (international, national, local) that correspond to step III of EBEI. Consistent with [15], one way of understanding information analysis is by critical thinking (i.e., when people determine the validity and value of the information). From this, it can be inferred that bimodal teachers have the competency to analyze information and critically evaluate it to link it to the development or formulation of an innovative project later.

Another characteristic of CDI is that the teacher can store and retrieve it. The quantitative findings determine a regular domain in item IIc of Table 1 regarding the teacher's understanding of the risks and advantages of storing information publicly or privately. This result is consistent with the guidelines stated by $[18,20]$ and researchers [14]. Consequently, it can be seen that bimodal teachers know and use technological tools and information storage and retrieval techniques, which allows them to be applied for specific purposes and contexts.

Among other teacher-DIC requirements is that of storing information in open or private sites. In this sense, the quantitative findings indicate that bimodal teachers have deficiencies (means below 3) in competencies IIa (2.88) and Ilb (2.43) in Table 1. These deficiencies are related to the storage of information in open access repositories, open sites (blog, wiki), and the aggregation of metadata and creative commons licenses to the information they produce and store. It is also corroborated by the results obtained qualitatively, where it can be seen that the information declared mainly highlights the use of the computer as the primary information storage technology. Therefore, we observed that there is a lack of knowledge of other storage sources. This aspect is essential for storing the selected information to integrate it in step III of EBEI (formulation of the innovation). However, these results contrast with those found in [19], where higher values were evidenced in teachers' storage and retrieval of information competency. From this, it can be inferred that it is necessary to reinforce training in this competence, emphasizing labeling or metadata management. The teacher must provide visibility of knowledge of open sites and stored information that facilitate collaborative work and the formulation of the innovative project, especially when it is a group project.

On the other hand, a teacher trained in DIC must know how to communicate information by different technological means. In this category, the quantitative results reflect high indexes in items IIIa and IIIb of Table 1 about selecting the technological means of communication that best suit teachers' purposes and transmit ideas in written and verbal form with synchronous and asynchronous communication technologies. Finally, we mention that these findings could be because the communication system of the institution under study is thoroughly planned (teaching plan). All of its bimodal professors must maintain continuous contact with the students of both study modalities (face-to-face and distance) through the EVA and synchronous tools such as Zoom, which aligns with the qualitative results. It is consistent with what is indicated by [21] on communicating information effectively through acquired knowledge and relevant competencies. These results infer that bimodal teachers are trained and can communicate in digital environments and share resources to perform their tasks or specific purposes effectively.

Being an informationally competent subject, moreover, means being able to disseminate information. However, in competency IIIc (2.79) in Table 1, the results also point out that teachers present deficiencies in disseminating the information they produce in open sites or private sites. However, these findings contrast with the results found qualitatively. The teachers indicated that the information they construct is disseminated mainly in journals (open or closed), refereed conferences, events of the institution, among others. That coincides with the results found in the tasks completing step VI of EBEI (publication and dissemination of innovation). The participants indicated their interest in disseminating innovations in open or closed technological media. Hence, we recommend disseminating the 
information (results of innovations or research) and avoiding a substantial delay, especially scientific information in open access [22]. These results infer that it is necessary to reinforce the competencies and motivation to disseminate more information about innovations in open sites that contribute to broadening knowledge.

Another fundamental characteristic of DIC is knowing how to use information appropriately. The quantitative findings showed that bimodal teachers perceive themselves as having good competencies in the items IVa, IVb, IVc, and IVd. These results are also favored because the teaching plan establishes the use of OER (videos, images, articles, open software, among others) to reinforce learning and teaching research. Thus, consulting and citing articles in open databases to support research is a factor to be considered. In addition, bimodal teachers promote using OER with their colleagues, students, and stakeholders in their environment. For this, they consider the steps described qualitatively about how the teachers use and process the selected information to build new knowledge and formulate, implement, and evaluate innovation (steps III, IV, and V). These findings are corroborated by [17], who mentions that teachers prefer to consult information in open sites. Additionally, [18] points out that those who possess high skills in using and processing information can do it critically, synthesize it, and construct new knowledge. Therefore, when teachers process information critically, it can be inferred that it leads them to contrast information, synthesize ideas, respect authorship, and construct new knowledge, fulfilling steps III, IV, and $\mathrm{V}$ of EBEI in the task.

On the other hand, an informationally competent teacher should collaborate with other academic groups and help students become collaborative and engaged citizens. The quantitative results found in items IVe (2.81) and IVf (2.28) of Table 1 show that teachers perceive themselves as having low competencies in promoting open publishing among colleagues, students, and the environment and the intention to collaborate in academic networks for discussion and research.

However, these results contrast with those in the interview, where it was possible to appreciate the teachers' interest in publishing their innovations (step VI of EBEI) in peer-reviewed journals (open or closed), in peer-reviewed congresses, and institutional academic conferences. These spaces precisely allow the dissemination of information, collaboration, and exchange of experiences. These aspects are crucial and must necessarily be developed by the teacher to foster collaboration, exchange, and construction of knowledge as a collective learning process [23]. These results, moreover, are similar to those found by [17], who points out that only a minimal number of teachers choose to publish information openly. These results infer that the use of technological spaces to disseminate and communicate information, the results of innovation projects, and the advantages offered need to be encouraged throughout the academic community and especially among teachers.

In Education 4.0, the role of the teacher should be transformational. In developing the proposed innovation model, oriented to teachers renewing or updating their practices based on the analysis and dissemination of evidence, the DIC is necessary and relevant for the sequential fulfillment of the steps comprising it. This is consistent with SDG4 that seeks to improve the quality of education [36]. Therefore, it can be inferred that the proposed innovation model contributes to Education 4.0, and this model, in turn, has a close relationship with the DIC.

\section{Conclusions}

In the present research, the research question was defined as: What is the relationship between the perceived capacity of the teacher's digital competency and the fulfillment of the innovation actions based on EBEI? The following was found in this regard:

Teachers perceived themselves as having good digital competencies in information search, selection, and evaluation, which are necessary to carry out step I of EBEI. In step I, delimiting the object of innovation, teachers required these competencies to support their proposed changes in their teaching practices, evidenced in the task delivered. In addition, 
this competency helped them to have clarity about the necessary elements to achieve such change. First, they developed search techniques that helped them find and select the information of their interest with greater precision. Second, they critically evaluated the information found. Therefore, it is concluded that the teachers knew how to take advantage of the potential offered by the resources available on the internet to fulfill this step and support their teaching and research functions.

Additionally, the self-perceived information search, selection, and evaluation skills and the information storage skills favored the fulfillment of step II, search for evidence available in the bibliography or specialized sites. In this step, teachers demonstrated that their innovations proposed through the tasks were supported by evidence or bibliographic resources from open and private sources, in Spanish and English, which were considered under APA standards. In this way, their interest in the search and selection of OER as research resources was also evidenced. However, the results of their self-perception indicate that there should be more awareness about using OER for research and the OER characteristics and purposes, especially because the verification of the license of use is an aspect they do not consider relevant.

On the other hand, the self-perceptions of the competencies of information use helped fulfill step III, formulating the innovation. In this step, these competencies allowed the teacher to process the information of the previous step, contrast it with other authors, and synthesize the relevant information. They determine the value of the information according to the search purposes and then, based on this, make decisions, and proceed to create new knowledge through formulating the innovation. Therefore, it is concluded that the competencies of information use are strongly linked to step III of EBEI. This step, critical in fulfilling the other EBEI steps, should be taken attentively.

Additionally, the self-perceptions of evaluating and using information made it possible to determine compliance with steps IV and V of innovation, application, and evaluation. These competencies allowed the teacher to design or adapt the intervention phases to apply the innovation and assess it (i.e., through techniques and instruments). Based on these competencies, the teacher acquired inputs (evidence) that allowed him/her to determine the application and evaluate the innovation more precisely. However, for the fulfillment of these steps, research competencies are also required.

The self-perceptions of the communication and dissemination of information competencies are related to fulfilling step VI, publishing and disseminating the innovation. On the one hand, the competencies of communication of information allowed the teacher to choose the most appropriate technological means to communicate it. In contrast, the competency of publishing information allowed him/her to determine the space or place of dissemination (congresses or events). Thus, we conclude that teachers have the competencies to communicate by technological means (e.g., the EVA to share resources and innovations). However, it is also necessary to consider that to disseminate or publish the innovation effectively, the teacher must be motivated and not be affected by work overload. Consequently, we conclude that digital information competencies are closely related to fulfilling innovation actions based on EBEI, and we can say that the binomial digital competencies and innovations are correspondent.

Finally, this study provided a validated evidence-based innovation model within the framework of Education 4.0, which has six steps to be executed sequentially and inclusively (i.e., without omitting any step). This model allows teachers to analyze and disseminate innovative evidence to guide their professional performance; therefore, it is closely linked to the DIC that guides informed decision-making. Thus, in tune with Education 4.0, this model promotes research practice to facilitate changes in teacher performance; it can be applied in the classroom by the teacher or in teacher training programs. In addition, the findings of this study can provide information for training processes specifically to develop or improve digital and informational skills in teachers, researchers, administrators, and trainers seeking educational innovations. As a future line of research, we envision analyzing the perceived digital competencies of teachers versus their effective behavior. 
Author Contributions: Conceptualization, M.S.R.-M. and J.M.; methodology, C.P.S.-L.; software, C.P.S.-L.; validation, C.P.S.-L. and J.M.; formal analysis, C.P.S.-L.; investigation, C.P.S.-L.; resources, C.P.S.-L.; data curation, M.S.R.-M.; writing-original draft preparation, C.P.S.-L.; writing-review and editing, M.S.R.-M.; visualization, J.M.; supervision, J.M.; project administration, C.P.S.-L.; funding acquisition, C.P.S.-L. All authors have read and agreed to the published version of the manuscript.

Funding: This research was funded by Universidad Técnica Particular de Loja (Ecuador) and SENESCYT.

Informed Consent Statement: Informed consent was obtained from all subjects involved in the study.

Acknowledgments: This research work has been conducted under the Ph.D. Program on Education in the Knowledge Society at the University of Salamanca. The authors would like to thank the Universidad Técnica Particular de Loja (Ecuador) and SENESCYT for its scholarship to study this Ph.D. program. Additionally, the authors would like to acknowledge the support of the Writing Lab, Institute for the Future of Education, Tecnologico de Monterrey, Mexico, in the production of this work.

Conflicts of Interest: The authors declare no conflict of interest.

\section{References}

1. Hinostroza, E. TIC, educación y desarrollo social en América Latina y el Caribe. UNESCO 2017, 7, 1-30.

2. Ramírez-Montoya, M.S.; García-Peñalvo, F.J. Co-creation and open innovation: Systematic literature review. Comunicar 2018, 26, 9-18. [CrossRef]

3. Miranda, J.; Molina, A. Designing Hybrid Learning Programs in Higher Education by Applying Education 4.0: The Innovation Challenge Bootcamp as Case Study. In Proceedings of the 2020 IEEE Learning With MOOCS (LWMOOCS), Antigua Guatemala, Guatemala, 29 September-2 October 2020; pp. 31-36.

4. Miranda, J.; Navarrete1, C.; Noguez, J.; Molina-Espinosa, J.; Ramírez-Montoya, M.S.; Navarro-Tuch, S.A.; Bustamante-Bello, M.R.; Rosas-Fernández, J.B.; Arturo, M. The Core Components of Education 4.0 in Higher Education: Three Case Studies in Engineering Education. Comp. Elect. Eng. 2021, 93, 107278. [CrossRef]

5. Ramírez-Montoya, M.S.; Loaiza-Aguirre, M.I.; Zúñiga-Ojeda, A.; Portuguez-Castro, M. Characterization of the teaching profile within the framework of education 4.0. Future Internet 2021, 13, 91. [CrossRef]

6. Bañuelos Márquez, A.M. Educación 4.0. en las instituciones universitarias. In REDINE (Coord). Contribuciones de la Tecnología Digital en el Desarrollo Educativo y Social; Adaya Press: Elndhoven, The Netherlands, 2020.

7. López, H.A.; Ponce, P.; Molina, A.; Ramírez-Montoya, M.S.; Lopez-Caudana, E. Design framework based on tec21 educational model and education 4.0 implemented in a capstone project: A case study of an electric vehicle suspension system. Sustainability 2021, 13, 5768. [CrossRef]

8. Del Valle, D.; Celaya, R.; Ramírez-Montoya, M.S. Apropiación tecnológica en el movimiento educativo abierto: Un estudio de casos de prácticas educativas abiertas. Rev. Iberoam. Educ. 2015, 70, 149-166.

9. Zabalza, M. Ser profesor universitario hoy. La Cuestión Univ. 2016, 5, 68-80.

10. Sarango-Lapo, C.P.; Mena, J.; Ramírez-Montoya, M.S. Teachers' Digital Skills training by using the Educational Innovation based on Evidence methodology (EIBE). In Search and Research: Teacher Education for Contemporary Contexts; Mena, J., García-Valcárcel, A., García-Peñalvo, F., Martín, M., Eds.; Editions Universidad de Salamanca: Salamanca, Spain, 2017; pp. $1005-1014$.

11. Cook, B.; Smith, G.J.; Tankersley, M. Evidence-based practices in education. In APA Educational Psychology Handbook; Harris, K.R., Graham, S., Urdan, T., McCormick, C., Sinatra, G., Sweller, J., Eds.; American Psychological Association: Washington, DC, USA, 2012; Volume 1, pp. 495-527.

12. Echeverría, B.; Martínez, P. Revolución 4.0, Competencias, Educación y Orientación. Rev. Dig. Investig. Doc. Univ. 2018, 12, 4-34.

13. Cabero-Almenara, J. La formación en la era digital: Ambientes enriquecidos por la tecnología. Rev. Gestión De La Innovación En Educ. Super. 2017, 2, 41-64.

14. García Llorente, H.J.; Martínez-Abad, F.; Rodríguez-Conde, M. Validación de un instrumento de evaluación de competencias informacionales autopercibidas en educación secundaria obligatoria. An. De Doc. 2019, 22, 3-10. [CrossRef]

15. Area, M.; Guarro, A. La alfabetización informacional y digital: Fundamentos pedagógicos para la enseñanza y el aprendizaje competente. Rev. Española Docum. Científica 2012, 977, 46-74. [CrossRef]

16. Álvarez, J.F.; Gisbert, M. Grado de alfabetización informacional del profesorado de Secundaria en España: Creencias y autopercepciones. Comunicar 2015, 45, 187-194. [CrossRef]

17. Gallardo, K.; Lozano, A.; Elizondo, J. Innovación educativa en estudios de psicología educativa: Un mapeo sistemático. In Innovación Educativa: Tendencias Globales de Investigación e Implicaciones Prácticas; Ramírez-Montoya, M.S., Valenzuela, R., Eds.; Octaedro: Barcelona, España, 2019; pp. 23-38.

18. ACRL. Information Literacy Competency Standards for Higher Education. 2000. Available online: http://www.ala.org/acrl/ ilcomstan (accessed on 20 July 2021).

19. Moreno-Guerrero, A.J.; Miaja-Chippirraz, N.; Bueno-Pedrero, A.; Borrego-Otero, L. El área de información y alfabetización informacional de la competencia digital docente. Rev. Electrónica Educ. 2020, 24, 1-20. [CrossRef] 
20. Ala-Mutka, K. Mapping Digital Competence: Towards a Conceptual Understanding; Technical Report No. JRC67075; Publications Office of the European Union: Luxembourg, 2011.

21. Bielba-Calvo, M.; Martínez-Abad, F.; Herrera García, M.E.; Rodríguez-Conde, M. Diseño de un instrumento de evaluación de competencias informacionales en Educación Secundaria Obligatoria a través de la selección de indicadores clave. EKS 2015, 16, 124-143. [CrossRef]

22. Ramírez-Montoya, M.S. Acceso abierto y su repercusión en la Sociedad del Conocimiento: Reflexiones de casos prácticos en Latinoamérica. EKS 2015, 16, 103-118. [CrossRef]

23. Spiteri, M.; Chang Rundgren, S.N. Maltese primary teachers' digital competence: Implications for continuing professional development. Eur. J. Teach. Educ. 2017, 40, 521-534. [CrossRef]

24. Ghomi, M.; Redecker, C. Digital competence of educators (DigCompedu): Development and evaluation of a self-assessment instrument for teachers' digital competence. In Proceedings of the CSEDU 2019, Heraklion, Greece, 2-4 May 2019; pp. 541-548. [CrossRef]

25. Cabero-Almenara, J.; Barroso-Osuna, J.; Rodríguez-Gallego, M.; Palacios-Rodríguez, A. La competencia digital docente. El caso de las universidades andaluzas. Aula Abierta 2020, 49, 363-371. [CrossRef]

26. INTEF. Marco Común de Competencia Digital Docente. 2017. Available online: https:// tinyurl.com/ybk2uuge (accessed on 14 August 2021).

27. Ferrari, A. DIGCOMP: A Framework for Developing and Understanding Digital Competence in Europe. 2013. Available online: https: / / tinyurl.com/yc9at8t6 (accessed on 14 August 2021).

28. Creswell, J.A. Concise Introduction to Mixed Methods Research; SAGE Publications: Thousand Oaks, CA, USA, 2015.

29. Tashakkori, A.; Teddlie, C. Handbook of Mixed Methods in Social E Behavioral Research; SAGE Publications: Thousand Oaks, CA, USA, 2003.

30. Sarango-Lapo, C.P.; Mena, J.; Ramírez-Montoya, M.S.; Real, E. La escala de Competencia Digital y uso de Recursos Educativos Abiertos (CD-REA ): Factores asociados a la competencia de los docentes universitarios bimodales. RISTI 2020, 28, 545-558.

31. Sarango-Lapo, C.P.; Mena, J.; Ramírez-Montoya, M.S.; Real, E. Metodología EBEI e innovación educativa: El caso de los docentes universitarios bimodales. Profesorado Revista de Currículum yFormación del Profesorado. (under review).

32. Creswell, J.; Plano Clark, V.L.; Guttmann, M.L.; Hanson, E.E. Advanced mixed methods research design. In Handbook of Mixed Methods in Social and Behavioral Research; Tashakkori, A., Teddlie, C., Eds.; SAGE Publications: Thousand Oaks, CA, USA, 2003.

33. Bandura, A. Self-Efficacy: The Exercise of Control; Freeman \& Company Publishers: New York, NY, US, 1997.

34. Bandura, A. Self-efficacy: Toward a unifying theory of behavioral change. In The Self in Social Psychology. Key Readings in Social Psychology; Baumeiste, R.F., Ed.; Psychology Press/Taylor \& Francis: Philadelphia, PA, USA, 1999; pp. $285-298$.

35. Escudero-Nahón, A.; Ramírez-Montoya, M.S. El modelo y sus marcos. In Modelo de Continuidad de Servicios Educativos ante un Contexto de Emergencia y Sus Etapas de Crisis; Vicario-Solórzano, C.M., Huerta-Cuervo, R., Escudero-Nahón, A., Ramírez-Montoya, M.S., Espinosa-Díaz, Y., Solórzano-Murillo, M., Trejo-Parada, G.E., Eds.; CUDI-ANUIES: Mexico City, México, 2021 ; pp. 19-29.

36. ONU. Transformar Nuestro Mundo: La Agenda 2030 para el Desarrollo Sostenible. 2015. Available online: https://www.un.org/ ga/search/view_doc.asp?symbol=A/70/L.1\&Lang=S (accessed on 20 July 2021).

37. García-González, A.; Ramírez-Montoya, M.S. Instrumento de valoración de innovación educativa: Pilotaje de confiabilidad en situación de estrategias integradas en curso en línea. In Proceedings of the XV Congreso Nacional de Investigación Educativa, Consejo Mexicano de Investigación Educativa, Acapulco, México, 18-22 November 2019; pp. 1-13.

38. Fayomi, O.S.I.; Okokpujie, I.P.; Fayomi, G.U. An innovation concept towards bridging the gaps between teaching and research. Procedia Manuf. 2019, 35, 775-781. [CrossRef]

39. Ramírez-Montoya, M.S. Modelos y Estrategias de Enseñanza para Ambientes Innovadores; Editorial Digital: Monterrey, México, 2012.

40. Quintas Cruz, J.E.; Ramírez-Montoya, M.S.; Kabalen Vanek, D.M. Competencias de investigación e innovación en formación docente con Aprendizaje Basado en Investigación (ABI). In Proceedings of the Congreso Internacional de Innovación Educativa, Monterrey, México, 11-13 December 2017. 